\title{
Non-linear multiple regression analysis for predicting seasonal streamflow using large scale climate mode
}

\author{
$\underline{\text { R.I. Esha }}^{a}$ and M.A. Imteaz ${ }^{\mathrm{a}}$ \\ ${ }^{a}$ Department of Civil and Construction Engineering, Swinburne University of Technology, Melbourne, \\ Australia \\ Email: resha@,swin.edu.au
}

\begin{abstract}
New South Wales which is one of the major contributors of Australia's agricultural income, often undergoes extreme climate conditions like droughts and floods due to its geographical location and climatic inconsistency, resulting in high inter-annual variation in streamflow. This study presents a solution to this problem developing streamflow prediction models with long lead time scale using the statistical Multiple NonLinear Regression (MNLR) techniques. While most of the past studies were concentrated on revealing the relationship between streamflow and single concurrent or lagged climate indices, current endeavour is to explore the combined impacts of large scale climate drivers to forecast seasonal streamflow considering their relationship to be non-linear. Several oceanic and atmospheric climate indices are selected considering their influence on the streamflow of NSW which includes four major climate drivers of this region PDO (Pacific Decadal Oscillation), IPO (Inter Decadal Pacific Oscillation), IOD (Indian Ocean Dipole) and the ENSO (El Nino Southern Oscillation) indices. The developed models with all the possible combinations show significantly good results in terms of Pearson correlation(r), and Root Mean Square Error (RMSE). The outcomes of MNLR models are compared to the best models of Multiple Linear Regression(MLR) analysis which was performed in one of the previous studies of this research. MNLR models are evident to outperform the MLR models in terms of Pearson correlation ( $\mathrm{r}$ ) values in both calibration and validation stages, verifying the non-linear relationship between seasonal streamflow and large-scale climate drivers. The maximum correlations are obtained as $0.46,0.39,0.52$ in the calibration period and $0.71,0.85$ and 0.79 in the validation period for the Singleton, Coggan and North Cuerindi stations respectively. Though the correlation values are not very high, they are statistically significant. The time series plot of the observed and simulated streamflow for the best developed models, show the limitations of this study as the models fail to predict unusual phenomenon like droughts or floods. Sophisticated non-linear models are expected to provide better predictions; thus, such methods will be attributed to the extension of this research study.
\end{abstract}

Keywords: $\quad M N L R, M L R$, climate indices, streamflow, seasonal forecast 
Esha and Imteaz, Non-linear multiple regression analysis for predicting seasonal streamflow ...

\section{INTRODUCTION}

The geographic location and extensive topographic variations present high climatic inconsistency in Australia which results in even higher inter-annual streamflow variability across the country, which is almost twice of the rivers in any other part of the world (McMahon et al.1992). As a consequence, it causes much difficulties to the irrigators, agricultural producers, water managers and planners to allocate irrigation water and environmental flows, manage and operate reservoir, supply municipal water, estimate future hydroelectricity supply etc.

Australia being surrounded by Pacific, Indian and Southern Ocean, is greatly influenced by the climatic anomalies originated from the ocean. It has been accepted by the hydrologists that there exists strong correlation between streamflow and large-scale atmospheric circulation patterns. The climate of southeast Australia is influenced by four major climate drivers (Duc et al. 2017) originating in the Pacific Ocean, the Indian Ocean and the Southern Ocean are El Niño Southern Oscillation (ENSO), the Interdecadal Pacific Oscillation (IPO) or Pacific Decadal Oscillation (PDO), Southern Annular mode(SAM) and Indian Ocean Dipole (IOD).

The ENSO phenomenon, which results from the large-scale interactions between ocean and atmospheric circulation processes in the equatorial Pacific Ocean, has direct influences on the climate variability over many parts of the world (e.g. Ropelewski \& Halpert, 1987). El Nino and La Nina events are responsible for the different climatic conditions around the Pacific including eastern Australia (Stone \& Auliciems, 1992). Several studies revealed the influences of ENSO on streamflow throughout Australia (Piechota et al., 1998; Chiew et al. 1998, Dutta et al. 2006). Chiew et al. (1998) and Piechota et al. (1998) found that ENSO based (SOI and SST) streamflow predictions in northeast Australia are better than the forecasts from climatology. Robertson and Wang (2009) explored the anomalies related to ENSO to be the best predictors of seasonal streamflow while the greatest predictability occurred between September and December. These findings were similar to the previous findings (McBride and Nicholls 1983) that evidenced strongest correlations between seasonal rainfall of NSW and ENSO during spring. The study of Chiew et al. (2003) explained that spring rainfall and runoff had high correlation (0.3 to 0.5) against winter SOI throughout eastern Australia.

Some recent evidences show that Eastern Australia is also influenced by IOD as well as interdecadal modulation of ENSO as a result of the low frequency variability in the Pacific Ocean, which is referred as PDO (Westra and Sharma, 2008). Many researchers (e.g., Power et al., 1999; Kiem et al., 2003) have demonstrated the influence of IPO to be significant on rainfall and streamflow variation on a decadal to multidecadal timescale. King et al. (2013) suggested that the IPO plays a significant role in the frequency of major floods during the 1950s,1970s and 2010-2011. Verdon et al. (2004) explained the enhanced rainfall and streamflow in eastern Australia to be the consequence of the combined impact of ENSO (La Nina) and IPO negative phase. Duc et al. (2017) showed in their study that IPO alone does not have any significant impact on rainfall of NSW but its combination with ENSO can make a significant impact on rainfall.

According to Qi and Chang (2011) the existing forecasting methods can be categorized into five parts, time series analysis, regression analysis, artificial intelligence method (e.g. ANN, fuzzy logic etc), the hybrid and Monte Carlo simulation methods (Haque et al., 2013). Various non-linear methods such as- ANFIS, ANN are widely applied in the field of hydro-climatology and water resources (Aqil et al. 2007, Dastorani et al., 2010). Recently artificial intelligence has attained popularity to forecast streamflow (Kumar et al. 2005; Kisi et al. 2007, 2008; Mutlu et al., 2008; Rezaeian et al., 2010). Again, dealing with artificial intelligence method is difficult which encourage the users to apply comparatively simple and straightforward statistical methods for instance regression models (Rezaeianzadeh et al., 2014). Data driven statistical models have gain popularity for their simplicity, accuracy, less information requirement and fast pace in model development (Adamowski 2008). Though the limitations of these models are evident when the data become complex. While forecasting streamflow, Chiew et al. (2003) suggested that non-linear regression methods can be applied to obtain higher correlations between streamflow and climate indicators by capturing the non-linear relationships between them. MNLR methods are usually applied for the accurate and fast prediction of random periodic events (Adamowski et al., 2012). In the study of Miyagashi et al. (1999) while forecasting temperature MNLR models outperformed the radial bias functions and numerical weather forecast methods.

This study has made an endeavor to forecast seasonal streamflow in north-east region of New South Wales which is a major agricultural state of Australia. To accomplish this objective multiple linear regression (Esha and Imteaz, 2017) and non-linear regression analysis are carried out where multiple climate indices are used as predictors of spring streamflow of the study region. Thus, the predictability of both the techniques are compared with a view to providing better streamflow forecast model. 


\section{STUDY AREA AND DATA}

Considering the geographical location, regional climatic variation and the agricultural importance, for the current study for the current research the north-east part of New South Wales is selected as the study area. Three streamflow stations (Figure 1) Hunter River at Singleton (Station ID 210001), Goulburn River at Coggan (Station Id 210006) and Namoi River at North Cuerindi (Station ID 419005) were selected based on their long data records and fewer missing values.

Historical streamflow data was collected from the Australian Bureau of Meteorology (http://www.bom.gov.au/waterdata/) for 102 years, ranging from 1914 to 2015 . These stations have less than $0.5 \%$ missing values, which are filled by the series mean of the stream flow data. Using this data, seasonal mean discharge data is derived for spring (September-October-November) season.

Considering previous research works on rainfall and streamflow in this region, four climate drivers: ENSO based SST anomalies NINO3.4, IPO, PDO, and DMI (IOD) were selected for the MNLR analysis. The five oceanic and atmospheric climate indices data were obtained from Climate Explorer website (http://climexp.knmi.nl) for a duration of 102 years (1914-2015).

ENSO phenomenon has two types of indicators, the SLP indicator and the SST indicator (Duc et al., 2017). Generally, the SST anomalies are monitored in 3 geographic regions (Figure 1) of the equatorial Pacific and defined as NINO3 $\left(5^{\circ} \mathrm{S}-5^{\circ} \mathrm{N}, 150^{\circ}-90^{\circ} \mathrm{W}\right), \mathrm{NINO} 3.4\left(5^{\circ} \mathrm{S}-\right.$ $\left.5^{\circ} \mathrm{N}, 170^{\circ}-120^{\circ} \mathrm{W}\right)$ and NINO4 (5 ${ }^{\circ} \mathrm{S}-$ $5^{\circ} \mathrm{N}, 160^{\circ}-150^{\circ} \mathrm{W}$ ) (Risbey et al., 2009).

The IOD represents the couples oceanicatmospheric variability in the tropical Indian Ocean which is classified by SST anomalies of reverse sign in the east and west (Saji et al., 1999; Webster et al. 1999). The Dipole Mode Index (DMI) which is a measure of the IOD is defined as the difference in SST anomaly between the tropical western Indian Ocean $\left(10^{\circ} \mathrm{S}-\right.$ $\left.10^{\circ} \mathrm{N}, 50^{\circ}-70^{\circ} \mathrm{E}\right)$ and the tropical south-

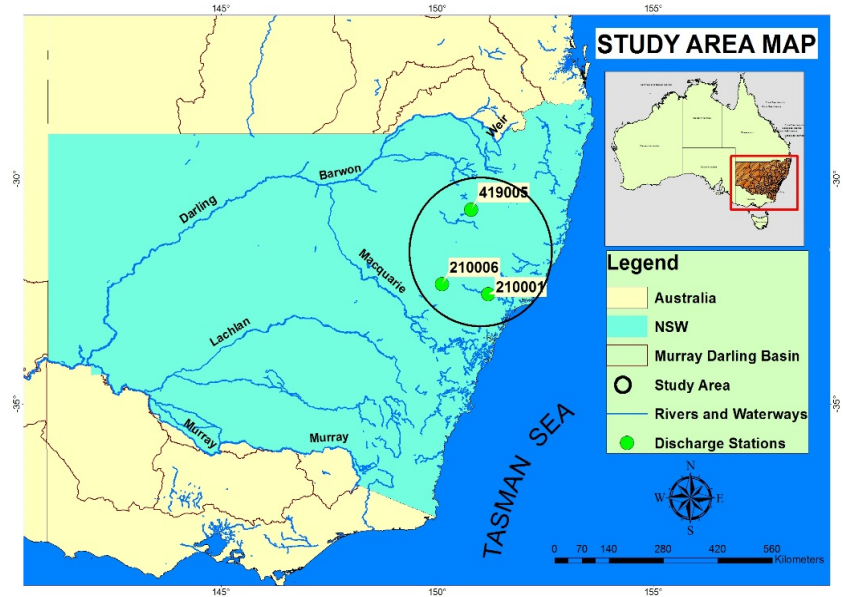

Figure 1. Map of the study area showing the locations of the streamflow stations. eastern Indian Ocean $\left(10^{\circ} \mathrm{S}-\right.$ equator, $90^{\circ}-$ $\left.110^{\circ} \mathrm{E}\right)$.

The IPO is described as the Pacific ENSO-like pattern of SST which is found in the analysis of near-global inter-decadal SST (Folland et al., 1999). IPO has a cycle of 15-30 years and characterized with two phases namely positive and negative (Henley et al., 2015). While IPO is defined for the whole Pacific Basin, PDO is defined for the North Pacific, pole ward of $20^{\circ} \mathrm{N}$.

\section{METHODOLOGY}

There are several engineering applications for exploring relationships between two or more parameters. Regression analysis model is one of the popular statistical approaches and is highly recommended for this kind of analysis (Mekanik et al., 2013). In one of the preliminary studies of this research MLR technique was applied for forecasting seasonal streamflow prediction for the same region as current study. In the present study, to make the regressions more flexible, NMLR models were applied with a view to comparing the predictability of both these techniques.

\subsection{Multiple non-linear regression analysis}

Regression methods can explain the relationships between a response (dependent) variable and several regressor (independent) variables (Tabari et al., 2010). In MLR, the function is linear which can be explained by the following equation

$$
Y=\alpha+\beta_{1} X_{1}+\beta_{2} X_{2}+\cdots .+\beta_{n} X_{n}
$$


Esha and Imteaz, Non-linear multiple regression analysis for predicting seasonal streamflow ...

Where $\mathrm{Y}$ is the dependent variable (e.g. streamflow for our study) and $X_{1}, X_{2}, \ldots X_{n}$ are the independent variables (climate indices e.g. ENSO, PDO, IPO etc.). $\beta_{1}, \beta_{2} \ldots \ldots \beta_{n}$ are the coefficients of the independent variables while $\alpha$ is the intercept or error and $\mathrm{n}$ is the number of observations.

Unlike traditional MLR methods, MNLR models are able to capture the arbitrary relationships between dependent and independent variables. The MNLR function is the non-linear combination of model parameters and depends on one or more independent variables (Bilgili 2010). The general form of a MNLR function can be represent by the following equation (Ivakhnenko, 1970):

$$
Y=\alpha+\beta_{1} X_{i}+\beta_{2} X_{j}+\beta_{3} X_{i}^{2}+\beta_{4} X_{j}^{2} \ldots+\beta_{n} X_{i} X_{j}
$$

Where $\alpha$ is the intercept and $\beta_{1}, \beta_{2} \ldots \ldots \beta_{n}$ are the coefficients of the independent variables while $\mathrm{n}$ is the number of observations.

One of the major problems of statistical analysis was to establish the appropriate relationship between the dependent variable and a set of independent variables. In order to find out the suitable relationship of each independent variable (climate indices), a series of simple regression analysis between the streamflow and climate variables were performed (Haque et al., 2013). Based on the correlation values (Pearson correlation, r) of this analysis the appropriate non-linear relationship for each variable is selected to develop the multiple nonlinear equation for predicting streamflow. Different functions including the exponential, power, cubic, logarithmic, quadratic and linear functions are used to identify the best relation.

The MNLR analysis in the present study was performed using Minitab software (Minitab, 2010). Different combinations of input variables were used to calibrate and validate the MNLR models. At first every MNLR model was calibrated using 85 years of data (1914-1998) which was followed by the validation of the models with the rest of 17 years (1999-2015) of data.

The performance of the developed MLR models (results obtained from the study of Esha and Imteaz, 2017) and MNLR models were assessed by two statistical performance measures, Pearson correlation value (r) and the Root Mean Square Error (RMSE). Similar approach for validating the results was applied by Mekanik et al. (2013) while predicting rainfall using climate indices. The ideal value for Pearson correlation is -1 which will refer to the best association between two variables where as a value of 0 will indicate there is no association. The lower value of the RMSE will indicate the better performance of the model.

\section{RESULTS AND DISCUSSION}

Different combinations of climate indices were selected based on the simple regression analysis. A sample of the results of simple regression analysis is presented in Table 1.

Table 1. Correlation coefficients of the simple regression analysis between climate indices and streamflow

\begin{tabular}{|c|c|c|c|c|c|c|c|}
\hline \multirow{2}{*}{$\begin{array}{c}\text { Station } \\
\text { Name }\end{array}$} & \multirow{2}{*}{$\begin{array}{c}\text { Independent } \\
\text { Variable }\end{array}$} & \multicolumn{6}{|c|}{ Correlation coefficient } \\
\cline { 2 - 8 } & Linear & Quadratic & Cubic & Power & Exponential & Logarithmic \\
\hline \multirow{3}{*}{ SINGLETON } & PDO $_{\text {JUNE }}$ & 0.257 & 0.266 & $\mathbf{0 . 2 6 7}$ & $*$ & 0.244 & $*$ \\
\cline { 2 - 8 } & NINO3.4 $_{\text {JUNE }}$ & 0.398 & 0.4 & $\mathbf{0 . 4 3 9}$ & $*$ & 0.369 & $*$ \\
\hline \multirow{2}{*}{\begin{tabular}{c} 
COGGAN \\
\cline { 2 - 8 }
\end{tabular}} & PDO $_{\text {AUG }}$ & 0.227 & 0.258 & $\mathbf{0 . 2 8 2}$ & $*$ & 0.258 & $*$ \\
\cline { 2 - 8 } & NINO3.4 $_{\text {AUG }}$ & 0.292 & 0.303 & $\mathbf{0 . 3 0 6}$ & $*$ & 0.3 & $*$ \\
\hline \multirow{2}{*}{ NUERTH } & PDO $_{\text {AUG }}$ & 0.286 & 0.342 & $\mathbf{0 . 4 0 9}$ & $*$ & 0.345 & $*$ \\
\cline { 2 - 8 } & NINO3.4 $_{\text {AUG }}$ & 0.364 & 0.372 & $\mathbf{0 . 3 8 6}$ & $*$ & 0.365 & $*$ \\
\hline
\end{tabular}

*Logarithmic and power models cannot be calculated due to mathematical error

The formation of the multiple non-linear equation can be explained by the following equation which is developed for Singleton station with the combination of two months lagged PDO and NINO3.4 where cubic functions are found to be more suitable for both the indices based on the correlation values (Table 1).

$$
\begin{gathered}
Q=\alpha+\beta_{1} * P D O_{J U N E}^{3}+\beta_{2} * P D O_{J U N E}^{2}+\beta_{3} * P D O_{J U N E}+\beta_{4} * N I N O 3.4_{J U N E}^{3}+\beta_{5} * N I N O 3.4_{J U N E}^{2}+ \\
\beta_{6} * N I N O 3.4_{J U N E}
\end{gathered}
$$

The performance of the best developed MLR (obtained from Esha and Imtiaz, 2017) and MNLR models in terms of the Pearson correlation (r) values for both calibration and validation stages are presented in Table 2. 
Esha and Imteaz, Non-linear multiple regression analysis for predicting seasonal streamflow ...

Table 2. Comparison of the performances of the MLR and MNLR models

\begin{tabular}{|c|c|c|c|c|c|c|c|c|c|}
\hline \multirow{3}{*}{$\begin{array}{l}\text { Station } \\
\text { Name }\end{array}$} & \multirow{3}{*}{ Model } & \multicolumn{4}{|c|}{ Calibration Period } & \multicolumn{4}{|c|}{ Validation Period } \\
\hline & & \multicolumn{2}{|c|}{ MLR } & \multicolumn{2}{|c|}{ MNLR } & \multicolumn{2}{|c|}{ MLR } & \multicolumn{2}{|c|}{ MNLR } \\
\hline & & $\mathbf{r}$ & RMSE & $\mathbf{r}$ & RMSE & $\mathbf{r}$ & RMSE & $\mathbf{r}$ & RMSE \\
\hline \multirow{2}{*}{ SINGLETON } & $\mathrm{PDO}_{\text {MAR_N_}}$ NINO3.4JUNE & 0.41 & 19.23 & 0.45 & 19.65 & 0.65 & 12.09 & 0.70 & 20.06 \\
\hline & PDO JUNE_NINO3.4 $_{\text {JUNE }}$ & 0.41 & 19.25 & 0.46 & 19.61 & 0.64 & 12.90 & 0.71 & 22.56 \\
\hline \multirow{2}{*}{ COGGAN } & $\mathrm{PDO}_{\mathrm{AUG}}{ }_{-} \mathrm{NINO} 3.4_{\mathrm{AUG}}$ & 0.30 & 2.18 & 0.39 & 2.19 & 0.70 & 1.21 & 0.85 & 2.058 \\
\hline & $\mathrm{PDO}_{\text {JUly_NINO3.4 }} 4_{\text {JUly }}$ & 0.33 & 2.15 & 0.38 & 2.21 & 0.61 & 1.25 & 0.76 & 1.74 \\
\hline \multirow{2}{*}{$\begin{array}{c}\text { NORTH } \\
\text { CUERINDI }\end{array}$} & $\mathrm{PDO}_{\text {AUG_NINO3.4 }} 4_{\text {AUG }}$ & 0.39 & 9.25 & 0.49 & 9.17 & 0.69 & 6.55 & 0.79 & 11.62 \\
\hline & $\mathrm{PDO}_{\text {JUly_NINO3.4 }} 4_{\text {JUly }}$ & 0.46 & 8.92 & 0.52 & 9.00 & 0.62 & 6.92 & 0.72 & 11.5 \\
\hline
\end{tabular}

While comparing the correlation values, the MNLR models outperformed the MLR models in both calibration and validation periods for all three stations. The maximum increment was $30 \%$ for the one month lagged combination at Coggan station in the calibration stage and $24.6 \%$ for the two months lagged combination at Coggan station in the validation stage. Again, the maximum correlation obtained in the calibration stage for MLR analysis was 0.46 for two months lagged PDO and NINO3.4 combination at North Cuerindi staion while for the same station and same combination MNLR model also obtained the maximum correlation which is 0.52. In the validation stage, the highest correlation values were provided by the two months lagged PDO_NINO3.4 combined models at Coggan station for both MLR $(\mathrm{r}=0.70)$ and MNLR ( $\mathrm{r}=0.85)$ models. The RMSE values were found to be relatively lower in the MLR models than the MNLR models.

It is clearly evident that every time there is significant increment of the correlation values from the calibration to validation stage. However, to get the best predictor model few unusual events which are outliers in a box-plot analysis, are removed from the calibration and validation periods. Thereby, the ratio of the duration of calibration or validation period to the number of outliers may have affected the corresponding correlation (r) values. It is to be noted that the analysis was performed for different the combinations of all four climate indices (NINO3.4, IOD, IPO and PDO), though only the performances of the best developed models are presented here (Table 2).

The ability of the best MLR model from each station to predict future streamflow has been explained through the time series plots of observed and simulated flows in
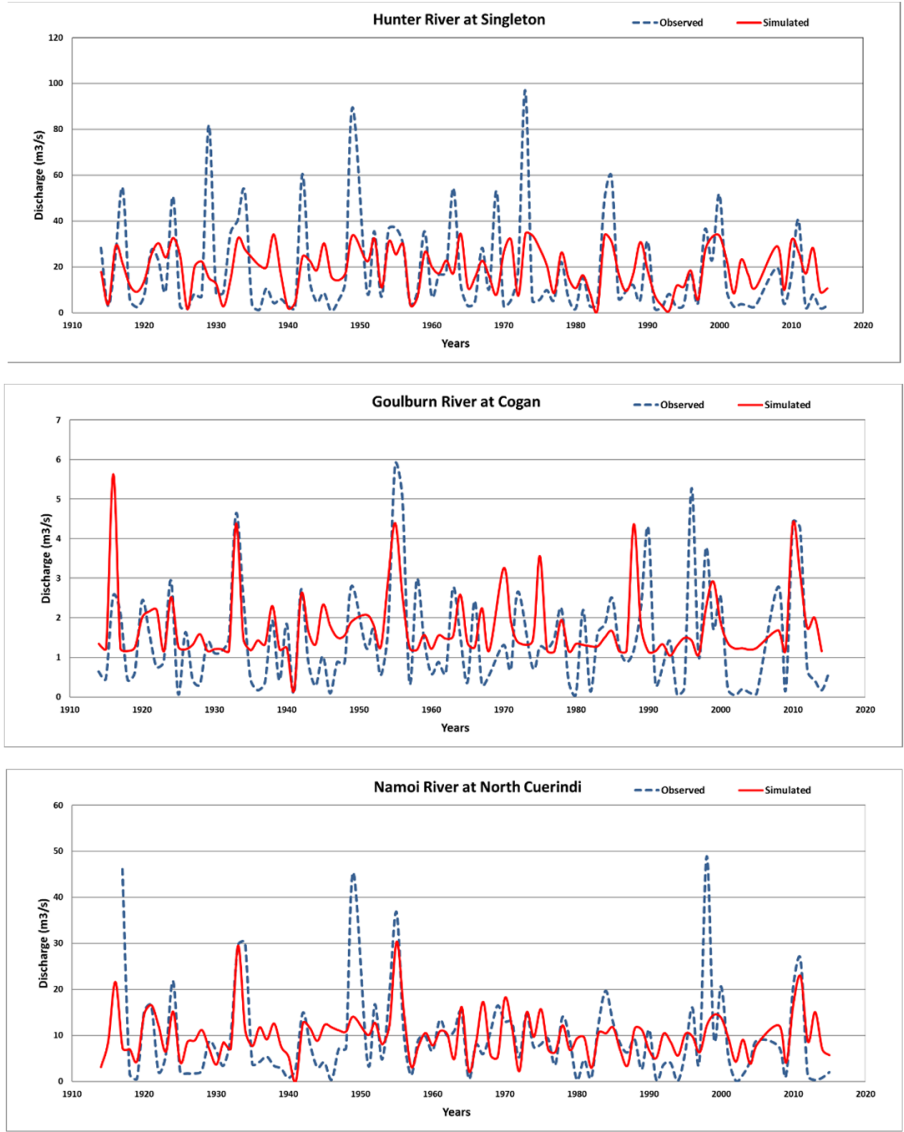

Figure 2. Comparison between the observed and simulated streamflow during the calibration (1914-1998) and validation (1999-2015) periods. 
Esha and Imteaz, Non-linear multiple regression analysis for predicting seasonal streamflow ...

In the time series plot some differences can be identified between the observed and simulated flow for few years. The reason can be that a regression model based on only two climate indices (e.g. PDO and NINO3.4) are not expected to capture the unusual phenomenon like severe droughts (e.g. millennium drought from 19942010) and floods. Another reason is that some other climate indices might have been more influential at that time rather than the selected indices in this study.

The best predictor models for each of the three stations are given below:

Discharge at station Singleton,

$$
Q=18.8478-0.139715 * P D O_{J U N E}^{3}+0.666786 * P D O_{J U N E}^{2}-1.21062 * P D O_{J U N E}+11.1097 *
$$

Discharge at station Cogan,

$$
\begin{array}{r}
Q=1.23771-0.0562763 * P D O_{A U G}^{3}+0.0979408 * P D O_{A U G}^{2}+0.00783779 * P D O_{A U G}- \\
0.292074 * N I N O 3.4_{A U G}^{3}+0.865392 * N I N O 3.4_{A U G}^{2}-0.53604 * N I N O 3.4_{A U G}
\end{array}
$$

Discharge at station North Cuerindi,

$$
\begin{gathered}
Q=8.40475-0.510611 * P D O_{A U G}^{3}+1.15553 * P D O_{A U G}^{2}+0.651763 * P D O_{A U G}+1.5338 * \\
N I N O 3.4_{A U G}^{3}-0.811479 * N I N 03.4_{A U G}^{2}-6.28591 * N I N O 3.4_{A U G}
\end{gathered}
$$

\section{CONCLUSION}

In this study, non-linear regression models were developed with the combination of different climate indices to forecast spring streamflow of the north-east region of NSW. The performance of the developed MNLR models were compared to the MLR models which were developed in a preliminary study of this research (Esha and Imteaz, 2017). From the best developed models, every time MNLR model outperformed the MNR models with higher correlation values which ensure the better predictability of the MNLR models over MLR models. Though the correlations were not very high, the results were statistically significant in terms of the RMSE values. The developed models enable the water users to forecast the spring streamflow with a maximum lagged time of two months. The limitation of the study is found in the time series plot as it failed to predict unusual events like floods or droughts. But simple regression models consisting of only two variables are not expected to capture such unexpected phenomenon. To explore the better predictive skills for long-term streamflow forecast more sophisticated models will be included in the extension of this research study.

\section{REFERENCES}

Adamowski, J. F. (2008). Development of a short-term river flood forecasting method for snowmelt driven floods based on wavelet and cross-wavelet analysis. Journal of Hydrology, 353(3), 247-266.

Adamowski, J., Fung Chan, H., Prasher, S. O., Ozga-Zielinski, B., \& Sliusarieva, A. (2012). Comparison of multiple linear and nonlinear regression, autoregressive integrated moving average, artificial neural network, and wavelet artificial neural network methods for urban water demand forecasting in Montreal, Canada. Water Resources Research, 48(1).

Aqil, M., Kita, I., Yano, A., \& Nishiyama, S. (2007). A comparative study of artificial neural networks and neuro-fuzzy in continuous modeling of the daily and hourly behaviour of runoff. Journal of hydrology, 337(1), 22-34.

Bilgili, M. (2010). Prediction of soil temperature using regression and artificial neural network models. Meteorology and atmospheric physics, 110(1-2), 59-70.

Chiew, F. H., Piechota, T. C., Dracup, J. A., \& McMahon, T. A. (1998). El Nino/Southern Oscillation and Australian rainfall, streamflow and drought: Links and potential for forecasting. Journal of Hydrology, 204(1-4), 138-149.

Chiew, F. H. S., \& Leahy, M. J. (2003). Inter-decadal Pacific oscillation modulation of the impact of El Niño/Southern Oscillation on Australian rainfall and streamflow. In MODSIM 2003: International Congress on Modelling and Simulation, Vol 1, 100-105.

Dastorani, M. T., Moghadamnia, A., Piri, J., \& Rico-Ramirez, M. (2010). Application of ANN and ANFIS models for reconstructing missing flow data. Environmental monitoring and assessment, 166(1), 421-434.

Duc, H. N., Rivett, K., MacSween, K., \& Le-Anh, L. (2017). Association of climate drivers with rainfall in New South Wales, Australia, using Bayesian Model Averaging. Theoretical and Applied Climatology, 127(1-2), 169-185. 
Esha and Imteaz, Non-linear multiple regression analysis for predicting seasonal streamflow ...

Folland, C. K., Parker, D. E., Colman, A. W., and Washington, R. (1999). Large scale modes of ocean surface temperature since the late nineteenth century. In Beyond El Niño (pp. 73-102). Springer Berlin Heidelberg.

Haque, M. M., Rahman, A., Hagare, D., \& Kibria, G. (2013, June). A comparison of linear and nonlinear regression modelling for forecasting long term urban water demand: A Case Study for Blue Mountains Water Supply System in Australia. In Water \& Environment Dynamics: Proceedings of the 6th International Conference on Water Resources and Environment Research, 3-7 June 2013, Koblenz, Germany (pp. 363373).

Henley, B. J., Gergis, J., Karoly, D. J., Power, S., Kennedy, J., \& Folland, C. K. (2015). A tripole index for the Interdecadal Pacific Oscillation. Climate dynamics, 45(11-12), 3077-3090.

Ivakhnenko, A. G. (1970). Heuristic self-organization in problems of engineering cybernetics. Automatica, 6(2), 207-219.

Kiem, A. S., Franks, S. W., \& Kuczera, G. (2003). Multi-decadal variability of flood risk. Geophysical Research Letters, 30(2).

King, A. D., Alexander, L. V., \& Donat, M. G. (2013). Asymmetry in the response of eastern Australia extreme rainfall to low-frequency Pacific variability. Geophysical Research Letters, 40(10), 2271-2277.

Kişi, Ö. (2007). Streamflow forecasting using different artificial neural network algorithms. Journal of Hydrologic Engineering, 12(5), 532-539.

Kişi, Ö. (2008). River flow forecasting and estimation using different artificial neural network techniques. Hydrology Research, 39(1), 27-40.

Krstanovic, P. F., \& Singh, V. P. (1991). A univariate model for long-term streamflow forecasting. Stochastic hydrology and hydraulics, 5(3), 173-188.

McBride, J. L., \& Nicholls, N. (1983). Seasonal relationships between Australian rainfall and the Southern Oscillation. Monthly Weather Review, 111(10), 1998-2004.

McMahon, T. A., Finlayson, B. L., Haines, A. T., \& Srikanthan, R. (1992). Global runoff: continental comparisons of annual flows and peak discharges. Catena Verlag.

Mutlu, E., Chaubey, I., Hexmoor, H., \& Bajwa, S. G. (2008). Comparison of artificial neural network models for hydrologic predictions at multiple gauging stations in an agricultural watershed. Hydrological processes, 22(26), 5097-5106.

Piechota, T. C., Chiew, F. H., Dracup, J. A., \& McMahon, T. A. (1998). Seasonal streamflow forecasting in eastern Australia and the El Niño-Southern Oscillation. Water Resources Research, 34(11), 3035-3044.

Power, S., Casey, T., Folland, C., Colman, A., \& Mehta, V. (1999). Inter-decadal modulation of the impact of ENSO on Australia. Climate Dynamics, 15(5), 319-324.

Qi, C., \& Chang, N. B. (2011). System dynamics modeling for municipal water demand estimation in an urban region under uncertain economic impacts. Journal of environmental management, 92(6), 1628-1641.

Rezaeianzadeh, M., Tabari, H., Yazdi, A. A., Isik, S., \& Kalin, L. (2014). Flood flow forecasting using ANN, ANFIS and regression models. Neural Computing and Applications, 25(1), 25-37.

Risbey, J. S., Pook, M. J., McIntosh, P. C., Wheeler, M. C., \& Hendon, H. H. (2009). On the remote drivers of rainfall variability in Australia. Monthly Weather Review, 137(10), 3233-3253.

Robertson, D. E., \& Wang, Q. J. (2009). A Bayesian joint probability approach to seasonal prediction of streamflows: Predictor selection and skill assessment. In H2009: 32nd Hydrology and Water Resources Symposium, Newcastle: Adapting to Change (p. 1545). Engineers Australia.

Ropelewski, C. F., \& Halpert, M. S. (1987). Global and regional scale precipitation patterns associated with the El Niño/Southern Oscillation. Monthly weather review, 115(8), 1606-1626.

Saji, N. H., Goswami, B. N., Vinayachandran, P. N., \& Yamagata, T. (1999). A dipole mode in the tropical Indian Ocean. Nature, 401(6751), 360.

Senthil Kumar, A. R., Sudheer, K. P., Jain, S. K., \& Agarwal, P. K. (2005). Rainfall-runoff modelling using artificial neural networks: comparison of network types. Hydrological Processes, 19(6), 1277-1291.

Stone, R., \& Auliciems, A. (1992). SOI phase relationships with rainfall in eastern Australia. International Journal of Climatology, 12(6), 625-636.

Tabari, H., Marofi, S., \& Sabziparvar, A. A. (2010). Estimation of daily pan evaporation using artificial neural network and multivariate non-linear regression. Irrigation Science, 28(5), 399-406.

Verdon, D. C., Wyatt, A. M., Kiem, A. S., \& Franks, S. W. (2004). Multidecadal variability of rainfall and streamflow: Eastern Australia. Water Resources Research, 40(10).

Webster, P. J., Moore, A. M., Loschnigg, J. P., \& Leben, R. R. (1999). Coupled ocean-atmosphere dynamics in the Indian Ocean during 1997-98. Nature, 401(6751), 356.

Westra, S., Sharma, A., Brown, C., \& Lall, U. (2008). Multivariate streamflow forecasting using independent component analysis. Water Resources Research, 44(2). 